\title{
Monoclonal Antibodies Reveal Cell-Type-Specific Antigens in the Sexually Dimorphic Olfactory System of Manduca sexta. I. Generation of Monoclonal Antibodies and Partial Characterization of the Antigens
}

\author{
Akira Hishinuma, ${ }^{1, a}$ Susan Hockfield, ${ }^{2, b}$ Ronald McKay, ${ }^{2, c}$ and John G. Hildebrand ${ }^{1, a}$ \\ 'Department of Biological Sciences, Columbia University, New York, New York 10027, and ${ }^{2}$ Cold Spring Harbor \\ Laboratory, Cold Spring Harbor, New York 11724
}

The olfactory system of the moth Manduca sexta is sexually dimorphic. Male moths possess a male-specific olfactory "subsystem," comprising olfactory receptor cells (ORCs) and CNS neurons and synaptic areas associated with the detection of female sex pheromones, in addition to elements common to males and females. In order to explore the molecular differences between cells that subserve the sexual dimorphism and odor-specificity of components of the olfactory system, we generated monoclonal antibodies (Mabs) against tissue of the olfactory system of the moth. In 2 fusions, we screened 1105 hybridoma lines and obtained 272 lines that secreted antibodies against Manduca nervous tissue, as assayed immunocytochemically on sections of the primary olfactory center (the antennal lobe) in the brain of Manduca. We describe here 3 classes of Mabs exemplifying the several cell-type-specific antibodies obtained through the screening procedure.

Seven hybridoma lines secrete antibodies that specifically recognize cell bodies, axons, and initial segments of dendrites of many or all ORCs of both males and females (classified as olfactory-specific antibodies, OSAs). Electron-microscopic studies of 2 of the Mabs in this class showed that they recognize antigens associated with the cell membrane and that the immunoreactive ORC axons are bundled together in fascicles in the antennal nerve. On immunoblots, one of the OSA Mabs recognizes 3 distinct protein bands of apparent $M_{r} s 42,000,59,000$, and $66,000 \mathrm{Da}$. When tissue samples enriched in either receptor cell bodies, dendrites,

\footnotetext{
Received April 16, 1987; revised June 23, 1987; accepted June 24, 1987.

We dedicate this paper to the memory of our colleague Dr. Stephen Schuetze, who generously gave us much help and encouragement in this project.

We are grateful to E. Waldvogel, C. Bautista, R. A. Montague, J. Suhan, E. Slattery, and N. Antinoro for expert technical assistance in various aspects of this research; Dr. K.-E. Kaissling for Antheraea polyphemus pupae; Dr. R. A. Akeson for his antibody 2B8; and Drs. J. Buckner and J. Svoboda of the USDA for Manduca eggs. We thank Dr. S. Hoskins, Dr. U. Homberg, and M. Stengl for their critical reading of the manuscript, Drs. L. Eckhardt, T. Kingan, and C. Squires for helpful discussions, and S. Garner for preparing the typescript. This research was supported by NSF Grants BNS 83-12769 and BNS 86-41145 (to J.G.H.) and BNS 84-19240 (to S.H.), and by NIH Grants IROI EY 065II (to S.H.) and IR01 NS 17556 (to R.M.). S.H. is a Klingenstein Fellow.

Correspondence should be addressed to John G. Hildebrand, ARL Division of Neurobiolugy, University of Arizona, 611 Gould-Simpson Science Building, Tucson, AZ 85721.

a Present address: ARL Division of Neurobiology, University of Arizona, Tucson, $\Lambda Z 85721$.

b Present address: Section of Neuroanatomy, Yale University School of Medicine, New Haven, CT 06510.

' Present address: MIT, Whitaker College, Cambridge, MA 02139.

Copyright (c) 1988 Society for Neuroscience 0270-6474/88/010296-12\$02.00/0
}

and initial segments of axons or in distal segments of axons and their terminals and synapses were extracted separately, different patterns of bands were detected-42,000 and 59,000 Da bands from cell bodies and initial segments of axons and dendrites, and 42,000 and 66,000 Da bands from distal seg. ments of axons and their terminals-suggesting that the 59,000 Da protein is modified to the 66,000 Da protein during axonal transport. The second Mab we describe here, the male olfactory-specific antibody (MOSA), selectively recognizes the sexually dimorphic ORCs that are present only in males. The antigen recognized by this antibody is found in cell bodies, dendrites, axons, and axon terminals. By electron-microscopic immunocytochemistry, the MOSA immunoreactivity is found in the cytoplasm and appears not to be associated with particular subcellular organelles. This antibody demonstrates that male-specific ORCs are molecularly distinct from other types of ORCs. The third antibody, the mechanosensory-preferring antibody (MPA), recognizes the mechanosensory receptor cells of the antenna but not the ORCs; it also recognizes some other cells in the CNS. In electron micrographs, MPA appears to bind to intermediate filaments in mechanoreceptor cells.

The organization and development of the sexually dimorphic antennal olfactory system of the sphinx moth Manduca sexta have been studied extensively (Hildebrand, 1985; Schneiderman and Hildebrand, 1985). In both males and females, olfactory receptor cells (ORCs), the somata of which are located in the epithelium beneath the cuticle of the antenna, send their dendrites into the sensilla arising from the antennal cuticle. The antenna bears several types of sensilla, including long sensilla trichodea, which are found only in males, and shorter sensilla basiconica, which are found in both males and females (Sanes and Hildebrand, 1976a). The sensilla trichodea possess malespecific ORCs that are specialized for detection of female sex pheromones (Sanes and Hildebrand, 1976b; J. Hildebrand and K.-E. Kaissling, unpublished observations). All of the antennal ORCs send their axons through the lumen of the antenna in 2 sensory nerves, which merge at the base of the antenna to form a single antennal nerve (AN). The olfactory axons project into the antennal lobe $(\mathrm{AL})$, the first-order olfactory center in the brain, where they form synapses with the dendrites of AL neurons. All of the synapses so far recognized in the AL are confined to the condensed glomeruli in the AL neuropil (Tolbert and Hildebrand, 1981). Spheroidal "ordinary" glomeruli are present 
in ALs of both males and females, and a much larger, sexually dimorphic "macroglomerular complex" (MGC) is characteristic of male ALs (Matsumoto and Hildebrand, 1981).

In addition to the antennal olfactory pathway, a labial "accessory" olfactory pathway has also been described. Chemosensory cells that are believed to be ORCs reside in the labial pit organ (LPO) and send axons through the first labial nerve and the subesophageal ganglion into both ALs; these fibers terminate in a specific and distinct "LPO glomerulus" in each AL (Kent and Hildebrand, 1985; Lee et al., 1985; Kent et al., 1986).

Besides the predominant ORCs, the antennae of Manduca also possess mechanosensory receptor cells, located in the 2 basal segments and, to a much lesser degree, in the flagellar annuli, which mainly house ORCs. The mechanosensory axons from the fiagellar annuli are interspersed among ORC fibers in the $A N$, whereas the mechanosensory axons from the basal segments form a bundle in the AN separate and distinct from the olfactory bundles. This mechanosensory bundle in the AN bypasses the AL and projects to the neighboring "mechanosensory and motor center" of the deutocerebrum (Camazine and Hildebrand, 1979; Hildebrand et al., 1980).

The pheromone-receptor cells are determined genetically, as evidenced by experiments in which male antennal imaginal disks grafted into female hosts develop into normal male antennae containing physiologically responsive pheromone-receptor cells (Schneiderman et al., 1982). It can be hypothesized that the pheromone-receptor cells express male-specific genes not expressed in other ORCs, such as those present in both males and females that respond to host-plant odors. To probe for sexually dimorphic expression of proteins in the olfactory system of Manduca sexta, we used the hybridoma technique to generate monoclonal antibodics (Mabs) against ANs and ALs and screened the Mabs on tissue sections by immunocytochemistry.

Among several cell-type-specific Mabs, we isolated a male olfactory-specific antibody (MOSA), which selectively recognizes ORCs found only in male antennae. Two other classes of Mabs distinguish receptor cells of different sensory modalities. The olfactory-specific antibody (OSA) binds specifically and exclusively to many or all ORCs, including the male-specific ORCs. The mechanosensory-preferring antibody (MPA) recognizes the mechanosensory cells in the antennal system, as well as cells elsewhere in the CNS. We further characterized the antigens recognized by these Mabs by electron-microscopic immunocytochemistry and immunoblot analysis. Preliminary reports of these findings appeared earlier (Hishinuma et al., 1985; Hishinuma, 1986).

\section{Materials and Methods}

Animals. Manduca sexta (Lepidoptera: Sphingidae) were reared on an artificial diet (Bell and Joachim, 1976) on a long-day photoperiod regimen ( $17 \mathrm{hr}$ light, $7 \mathrm{hr}$ dark) at $26^{\circ} \mathrm{C}$, and staged as described previously (Sanes and Hildebrand, 1976a; Tolbert et al., 1983). The metamorphosis of the pupa to the adult normally occurs over 18 stages, each lasting approximately $1 \mathrm{~d}$, and ends with the emergence of the adult moth $19.8 \pm 1.3 \mathrm{~d}$ after the larval-pupal molt (Sanes and Hildebrand, 1976a; Tolbert et al., 1983). Pharate-adult Manduca within $24 \mathrm{hr}$ of adult eclosion were used in these studies.

To produce antennal gynandromorphs, we transplanted antennal imaginal disks between male and female fifth-instar larvae as described previously (Schneiderman et al., 1982; Schneiderman, 1984).

Production of monoclonal antibodies. Mabs were produced as described by Köhler and Milstein (1976). The Mabs described herc were obtained from 2 fusions for which the isolated ALs and intracranial segments of the ANs were used as the immunogen.
For each fusion, homogenates of the ALs and intracranial segments of the ANs from 20 male pharate adults were emulsified with complete Freund's adjuvant and used to immunize a single Balb/C mouse (Jackson Laboratory) intraperitoneally 3 times over a period of 5 months. For the final immunization (i.v.), the tissue was prepared in phosphate buffer. Four days after the last immunization, the mouse was killed, its spleen was removed, and spleen cells were dissociated and fused with NS-1 myeloma cells in 50\% polyethylene glycol (PEG 1000; Baker). The cells were plated in 3000 wells of 96 -well tissue culture plates (Linbro) and selected in HAT medium $\left(10^{-4} \mathrm{M}\right.$ hypoxanthine, $4 \times 10^{-7}$ $\mathrm{M}$ aminopterin, and $1.6 \times 10^{-5} \mathrm{M}$ thymidinc; all from Sigma).

From these 2 fusions, 1105 wells had hybridoma colonies. The culture media were tested immunocytochemically on free-floating, $40 \mu \mathrm{m}$ frozen sections of the male ALs. Hybridoma lines were stabilized by cloning in soft agar (Seakem) until every colony picked was positive.

Immunocytochemistry. For light-microscopic immunocytochemistry, freshly dissected tissue was fixed overnight in $4 \%$ formaldehyde in 0.1

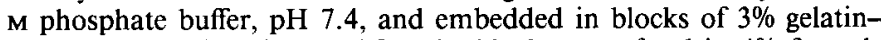
$30 \%$ egg albumin (Sigma). After the blocks were fixed in $4 \%$ formaldehyde, they were cryoprotected overnight in $30 \%$ sucrose, and then 40 $\mu \mathrm{m}$ frozen sections were cut on a sliding microtome. For better penetration of antibody, the sections were dehydrated through graded ethanols into xylene and then rehydrated (Hockfield and McKay, 1983). The sections were then incubated overnight in the culture supernatant media (full strength) with $2 \%$ Triton X-100 (Sigma), washed with phosphate buffer, incubated in rabbit anti-mouse IgG conjugated to HRP (diluted 1:100; Miles) and 2\% Triton X-100 for $2 \mathrm{hr}$, washed with phosphate buffer, and allowed to react with diaminobenzidine (DAB; Sigma) in the presence of $0.001 \% \mathrm{H}_{2} \mathrm{O}_{2}$. For intensification with cobalt, the sections were incubated for $10 \mathrm{~min}$ in $0.27 \% \mathrm{CoCl}_{2}$ in $0.1 \mathrm{M}$ Tris buffer, pH 7.8, before reaction with DAB (Adams, 1977).

For electron microscopy, tissue was fixed in $4 \%$ paraformaldehyde in $0.1 \mathrm{~m}$ phosphate buffer, $\mathrm{pH} 7.4$ or $\mathrm{pH} 10$ (for better tissue preservation pH 10 was used; Eldred et al., 1983), and embedded in gelatin-albumin. The blocks were fixed in $4 \%$ paraformaldehyde, and $50 \mu \mathrm{m}$ sections were cut with a Vibratome (Lancer). The sections were incubated with antibodies in the absence of Triton X-100, and the DAB reaction product was developed as described for light microscopy. In some experiments, colloidal gold-conjugatcd sccondary antibody was used to obtain better resolution of antibody-binding sites. In those experiments, the sections were incubated with goat anti-mouse IgG conjugated to colloidal gold $(20 \mathrm{~nm})$ (Janssen Life Sciences) overnight after reaction with the primary antibodies. The sections were then fixed in $2 \% \mathrm{OsO}_{4}$ (Stevens Metallurgical) in phosphate buffer for $2 \mathrm{hr}$ and embedded in EponAraldite. Because the antibodies penetrate only a few micrometers from the surface of the tissue, ultrathin sections were prepared selectively from this region and examined in the electron microscope (Philips 201c) with or without poststaining with lead citrate.

Immunoblots. Antennal epithelial tissue, containing cell bodies and proximal segments of axons and dendrites of the ORCs, was prepared by cutting the antenna open with iridectomy scissors and excising fragments of epithelium with fine forceps. To obtain tissue samples containing central (distal) scgments and terminals of the ORC axons, we isolated the ALs and attached intracranial segments of the ANs by dissection from the rest of the brain. The freshly excised tissues were homogenized in SDS sample buffer (2\% SDS, $5 \%$ glycerol, $0.001 \%$ bromphenol blue, $0.08 \mathrm{M}$ Tris- $\mathrm{HCl}, \mathrm{pH} 6.8$ ) in the presence of protease inhibitors (1 mM EDTA, $0.3 \mathrm{~mm}$ phenylmethylsulfonyl fluoride, $0.1 \mathrm{~mm}$ benzethonium $\mathrm{HCl}, 1 \mathrm{~mm}$ benzamidine, $5 \mu \mathrm{g} / \mathrm{ml}$ soybean trypsin inhibitor, $100 \mu \mathrm{g} / \mathrm{ml}$ bacitracin, $2 \mu \mathrm{g} / \mathrm{ml}$ leupeptin, all from Sigma; Shorr et al., 1981) with or without dithiothreitol (Sigma), boiled for $3 \mathrm{~min}$, and centrifuged at $2000 \mathrm{rpm}$ (IEC HN-SII centrifuge) for $5 \mathrm{~min}$. The solubilized samples were electrophoresed in an SDS polyacrylamide gel according to Laemmli (1970), and protein bands were transferred to nitrocellulose sheets (Schleicher and Schuell), as described by Towbin et al. (1979). Each sample was duplicated in 2 lanes, and after transfer one-half of the lanes were staincd with $4 \%$ amido black in $5 \%$ acetic acid and $45 \%$ methanol.

The rest of the lanes were processed for immunoblots. Nitrocellulose sheets were pretreated with 3\% bovine serum albumin (Sigma) in Tris saline (10 mM Tris, $150 \mathrm{~mm} \mathrm{NaCl}, \mathrm{pH} 7.5)$ with $0.05 \%$ Tween-20 (Sigma), and subsequently incubated in the supernatant media and in the HRP-conjugated anti-mouse IgG. The reaction product was visualized with 4-chloro-1-naphthol (Sigma) in the presence of $\mathrm{H}_{2} \mathrm{O}_{2}$. For subcellular fractionation, tissue was homogenized on ice in isotonic (300 

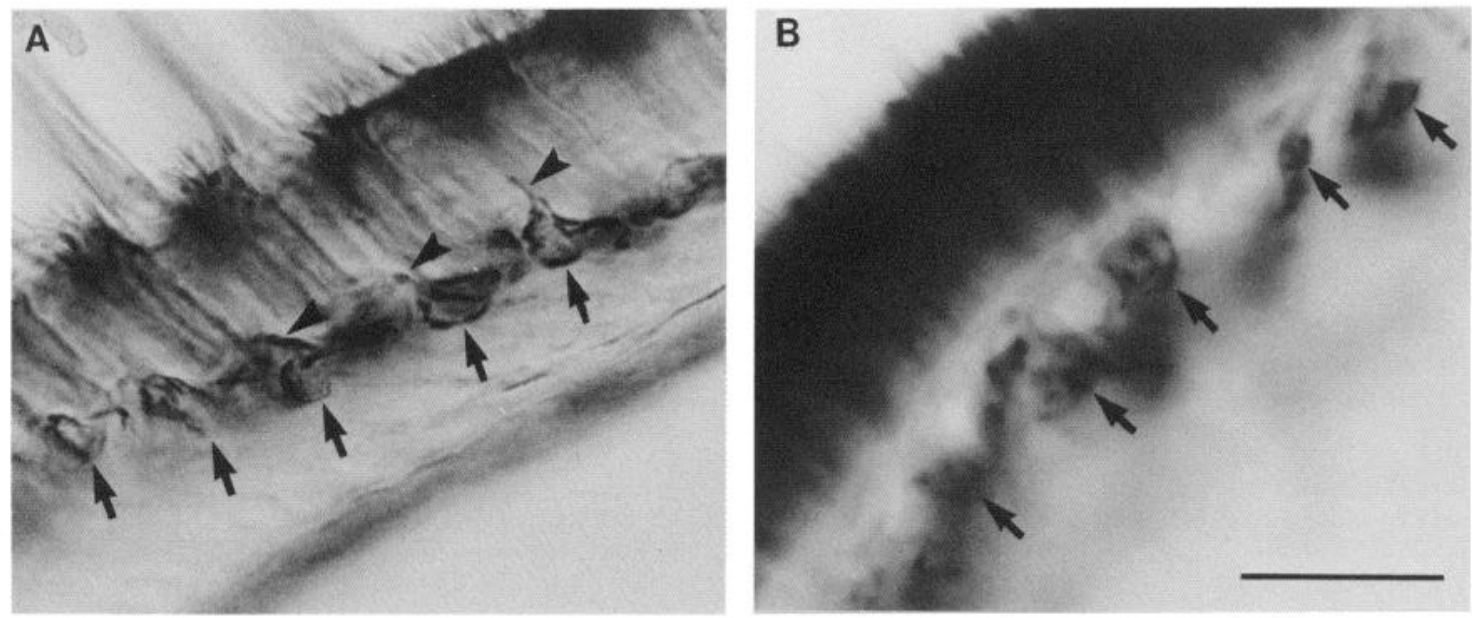

Figure 1. Immunostaining of the OSA in cross sections of the male $(A)$ and female $(B)$ antennae. Cell bodies (arrows) and initial segments of dendrites (arrowheads) of the ORCs lie beneath the hard cuticle, which is naturally dark. The OSA stains all ORCs in males and females. Bar, $100 \mu \mathrm{m}$.

mM) sucrose solution in the presence of protease inhibitors, using a glass homogenizer equipped with a Teflon pestle. After centrifugation at 10,000 rpm (Fisher micro-centrifuge) for 5 min, the supernatant fraction was further centrifuged at $100,000 \mathrm{rpm}$ (Beckman Airfuge) for $30 \mathrm{~min}$. The final pellet and the supernatant solution were subsequently used as crude membrane and cytosol fractions, respectively. The centrifuged materials were solubilized in the SDS sample buffer without dithiothreitol and electrophoresed for later immunoblotting. For digestion with endoglycosidase (to hydrolyze carbohydrate moieties of glycoproteins), tissue was homogenized on ice with 2\% NP-40 (Particle Data Laboratories) in $100 \mathrm{~mm} \mathrm{NaCl}, 10 \mathrm{~mm}$ citrate-phosphate buffer, $\mathrm{pH} \mathrm{5}$, with protease inhibitors, using a Teflon-on-glass homogenizer, and centrifuged at
$100,000 \mathrm{rpm}$ (Airfuge) for $30 \mathrm{~min}$. The supernatant fraction, derived from the antennae and ALs from 4 animals in $15 \mu \mathrm{l}$, was incubated with $2 \mathrm{mU}$ of endoglycosidase $\mathrm{H}$ (Boehringer-Mannheim) at $37^{\circ} \mathrm{C}$ for $1 \mathrm{hr}$, solubilized in the SDS sample buffer without dithiothreitol, and electrophoresed and processed for immunoblot analysis.

\section{Results}

\section{Fusions}

The Mabs with olfactory specificities described in this paper were isolated exclusively from 2 fusions for which homogenates
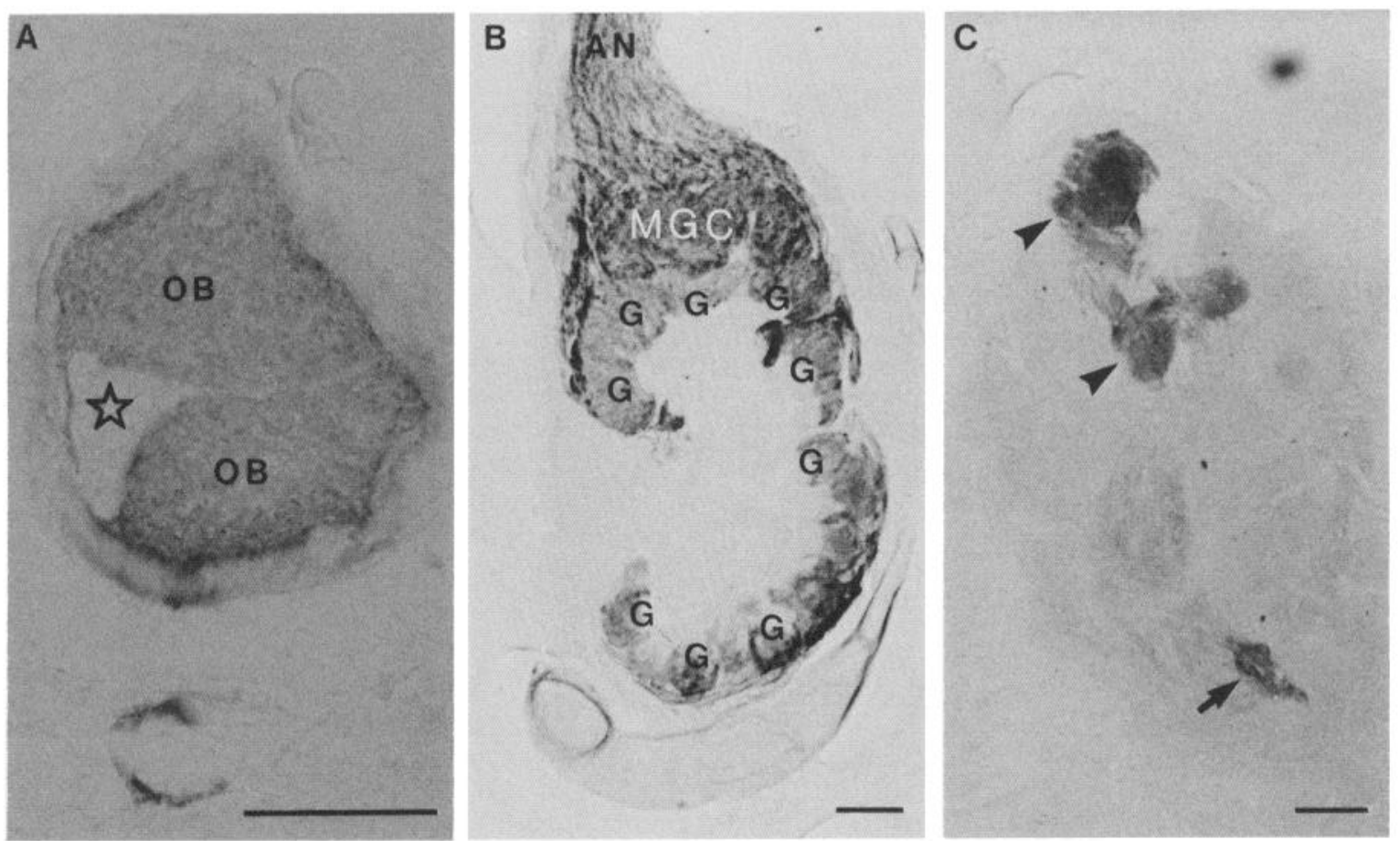

Figure 2. A, Cross section of the intracranial segment of a male AN stained by the OSA. The AN contains 3 bundles of axons: 2 olfactory bundles $(O B)$ and one mechanosensory bundle (star). The ORCs send their axons into the 2 olfactory bundles, which are stained by the OSA. The mechanosensory bundle is not stained by the OSA. B, Frontal section of a male AL stained by the OSA. The OSA-immunoreactive primary olfactory axons enter the perimeter of the AL through the AN and terminate in the glomeruli. Every glomerulus, i.e., the "ordinary" glomeruli ( $G$ ) common to males and females and the male-specific $M G C$, is stained by the OSA. C, LPO fiber tract (arrow), running through the subesophageal ganglion to the $\mathrm{AL}$, stained by the OSA. Parts of a few OSA-immunoreactive glomeruli in the AL also appear at this deep plane of section (arrowheads). Bars: $50 \mu \mathrm{m}(A) ; 100 \mu \mathrm{m}(B$ and $C)$. 

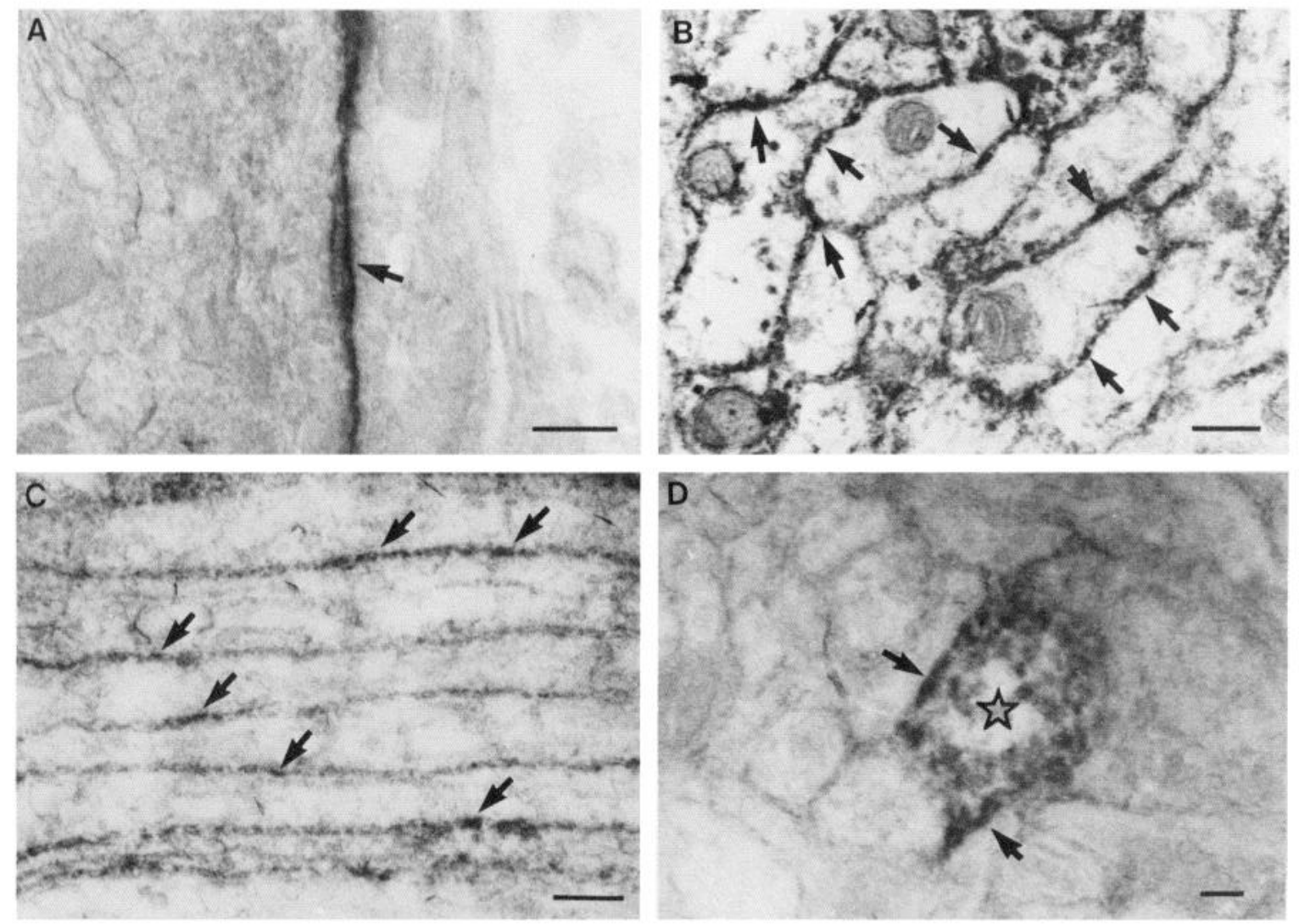

Figure 3. Electron-microscopic immunocytochemical labeling with the OSA using secondary antibody conjugated to HRP. The reaction product (arrows) is associated with the plasma membrane of cell bodies $(A)$, axons (cross sections, $B$; longitudinal sections, $C$ ), and axon terminals $(D)$ of the ORCs. In $B$ and $C$, the sections were poststained with lead citrate. In $D$, a single synaptic terminal (star) of an ORC is stained. The reaction product is associated with internal membranous structures as well as with the plasma membrane in $D$. Bars, $0.2 \mu \mathrm{m}$.

of ALs and ANs served as immunogen. Of 1105 hybridoma lines screened immunocytochemically on sections of male ALs, 272 were positive. Seven lines fell into the OSA class, but only one belonged to the MOSA class. The MOSA was found in the AL fusion without cyclophosphamide treatment. The MPA was found in both whole-brain fusions and AL fusions.

\section{Olfactory-specific antibody (OSA)}

The OSA stains many, and apparently all, ORCs in both males and females (Fig. 1). When the primary or the secondary antibody is omitted, no structures are stained. Reaction product in the ORCs is found in cell bodies, axons, and initial segments of dendrites. Immunoreactivity has not been detected in association with the outer segments of ORC dendrites. The OSA binds to the 2 nerves in the lumen of the antenna and to the corresponding 2 olfactory bundles in the intracranial segment of the AN, but not to its mechanosensory bundle (Fig. $2 A$ ). The axons of the ORCs terminate principally in the outer part of the glomeruli, as illustrated by immunostaining with the OSA (Fig. $2 B$ ). This pattern of immunostaining closely resembles the pattern that results from filling the olfactory axons with cobalt and precipitating it with sulfide (Camazine and Hildebrand, 1979; Kent, 1985). Every glomerulus in the AL is stained by the OSA. The OSA also stains the fiber tract from the LPO to the ALs (Fig. 2C), in each of which it terminates in the previously identified "LPO glomerulus" (Kent et al., 1986). When serial sections of the whole brain, subesophageal ganglion, and prothoracic ganglion were tested with the OSA, only the ORC axons and LPO fibers exhibited immunoreactivity (except for very faint staining in the mushroom bodies; not shown).

Electron-microscopic immunocytochemistry using an HRPconjugated secondary antibody showed that the antigens recognized by the OSA are associated with the plasma membranes of cell bodies (Fig. $3 \mathrm{~A}$ ) and axons (Fig. 3, B,C). The OSApositive axons are bundled together in fascicles in which the reaction product can be seen between juxtaposed axons.

We used the OSA to identify the synaptic terminals of the ORCs in the glomeruli of the AL. In electron micrographs of OSA-stained sections, immunoreactive synaptic terminals containing numerous vesicles are identified adjacent to the unstained terminals of $\mathrm{AL}$ neurons (Fig. $3 D$ ). The reaction product is associated not only with the plasma membrane but also with intracellular membranous structures, apparently including vesicles. Few such intracellular structures have been found to be stained in cell bodies and axons.

Biochemical analyses showed that the OSA recognizes more than one molecular species. Initially, standard procedures for immunoblotting (involving solubilization of samples in SDS sample buffer containing dithiothreitol) yielded no stained protein bands. Solubilization of tissue under nonreducing conditions, however, led to identification of stained bands on the immunoblots. We confine our discussion here to major bands, although tissue from insects at various stages of adult development consistently yielded 1-4 other minor bands as well 


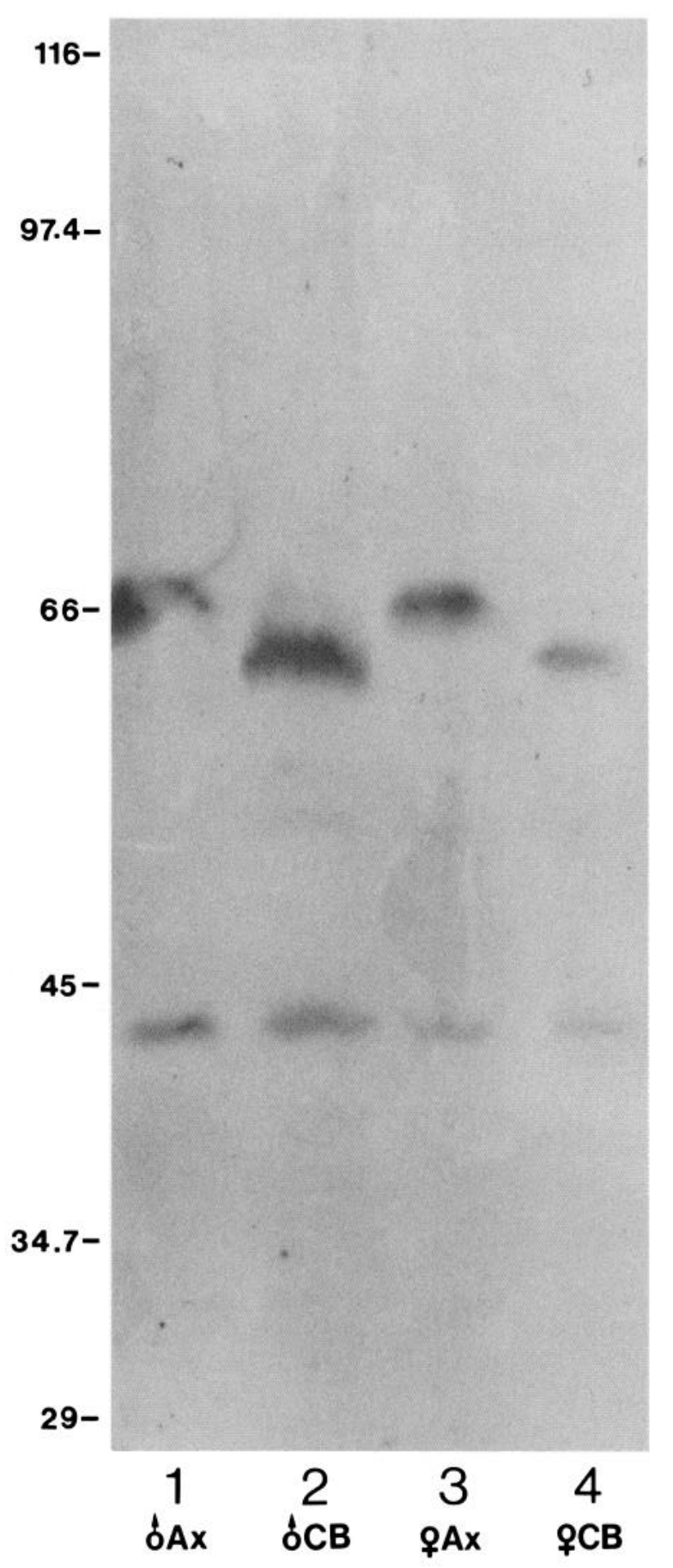

Figure 4. Immunoblot analysis of the OSA antigens. Lanes 1 and 3 show that 66,000 and $42,000 \mathrm{Da}$ bands are recognized by the OSA when extracts of tissue samples including ORC axon terminals and intracranial segments of the ANs are tested. Lanes 2 and 4 show that 59,000 and 42,000 Da immunoreactive bands are obtained from extracts of antennal tissue, including ORC cell bodies and proximal axon segments. There is no noticeable difference between males (lanes 1 and 2) and females (lanes 3 and 4 ), which yield the same number of immunoreactive bands and similar molecular weights. Molecular-weight markers (bars) are (in Da) carbonic anhydrase $(29,000)$, pepsin $(34,700)$, egg albumin $(45,000)$, bovine serum albumin $(66,000)$, phosphorylase $(97,400)$, and $\beta$-galactosidase $(116,000)$.

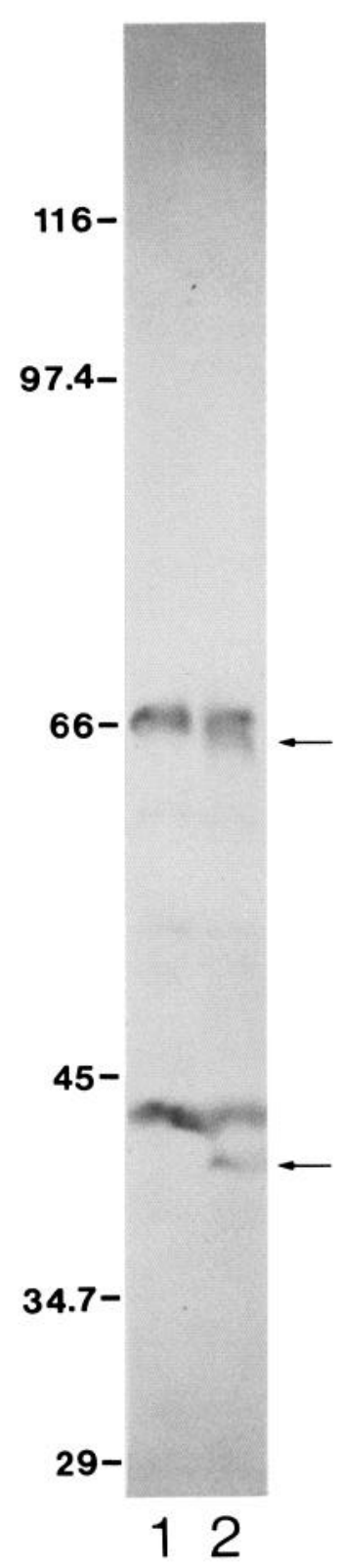

Figure 5. Endoglycosidase $\mathrm{H}$ treatment of NP-40-solubilized extract of $\mathrm{AL}, \mathrm{AN}$, and antennal tissue. Treatment with endoglycosidase $\mathrm{H}$ (lane 2) generated new immunoreactive bands at 64,000 and 40,000 Da (arrows) from the 66,000 and 42,000 Da proteins. These new bands did not appear after a control incubation $\left(37^{\circ} \mathrm{C}, 1 \mathrm{hr}\right)$ in the absence of endoglycosidase $\mathrm{H}$ (lane 1 ). Note that the $59,000 \mathrm{Da}$ band is missing in both of these samples.

(Hishinuma et al., 1988). The OSA binds to 2 major protein bands, of apparent $M_{\mathrm{r}} \mathrm{s} 59,000$ and 42,000 Da, from the ORC components in the antenna (somata and proximal segments of axons and dendrites). The ALs (distal segments and terminals of ORC axons) and intracranial ANs (central segments of ORC axons) yield 2 different bands, of apparent $M_{r} \mathrm{~s} 66,000$ and 42,000 Da (Fig. 4). Extracts of tissue from one antenna or 2 ALs were loaded onto each lane so that each carried a comparable amount of protein, as verified subsequently by amido black staining. Staining with amido black also showed that the immunoreactive bands did not correspond to the major proteins (data not shown). Comparison of immunoblots of electrophoresed tissue extracts 

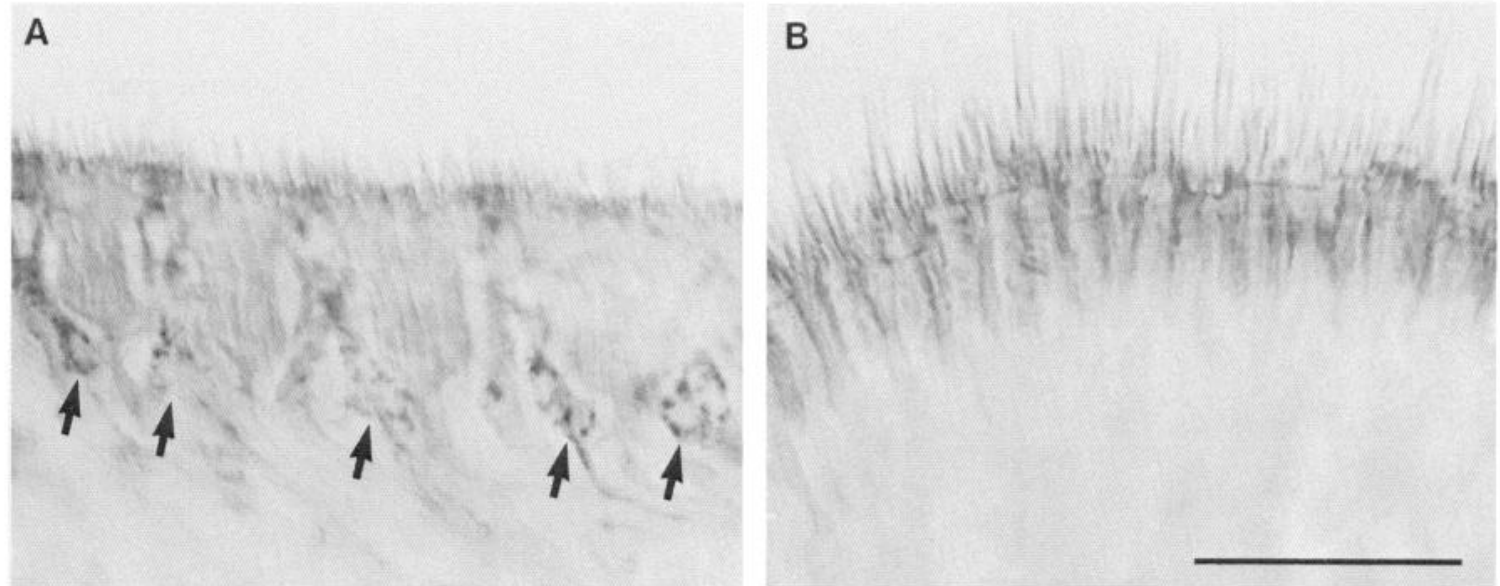

Figure 6. Immunostaining with the MOSA in cross sections of male $(A)$ and female $(B)$ antennae. The MOSA stains a subset of the ORCs in males (arrows) but not in females. Bar, $100 \mu \mathrm{m}$.

from males and females shows that the pattern of OSA-positive bands and their apparent molecular weights are the same in both sexes (Fig. 4). Another Mab (synapse-specific antibody; Hishinuma et al., 1985) of the same immunoglobulin subclass as the OSA (IgG1) did not stain the same bands recognized by the OSA.

To pursue the suggestion derived from the electron-microscopic observations that the antigens are associated with the plasma membrane, we fractionated tissue into crude membrane and cytosol fractions and tested these fractions for immunoreactivity on immunoblots. All 3 bands were recovered from the crude membrane fractions, but not detectably from the cytosol fractions (data not shown).

The tissue extracts were further solubilized with $2 \%$ NP-40 and digested by endoglycosidase $\mathrm{H}$ at $37^{\circ} \mathrm{C}$ for $1 \mathrm{hr}$ to determine whether the antigens were glycoproteins. The 66,000 and 42,000 Da bands were converted to new bands of slightly lower apparent molecular weights (64,000 and 40,000 Da, respectively, as shown in Fig. 5), confirming that the proteins are glycosylated. The 59,000 Da protein was missing in both the digested sample and the control (without endoglycosidase H) (Fig. 5). No protein bands were stained by the OSA on immunoblots of electrophoresed extracts of prothoracic ganglia, abdominal ganglia, muscle, and fat body, which do not receive primary olfactory projections (data not shown).

\section{Male olfactory-specific antibody (MOSA)}

The MOSA stains a subset of the antennal ORCs in males, but not in females (Fig. 6). The immunocytochemical reaction product obtained with this Mab is found in cell bodies (Fig. 6), dendrites (Fig. $7 A$ ), and axons (Fig. 7B). The only type of cell clearly stained by the MOSA is the receptor cell associated with the male-specific sensilla trichodea.

We used the MOSA to study the organization of axons and terminals of the male-specific ORCs. In cross sections of the intracranial segments of the ANs, staining with the MOSA re-
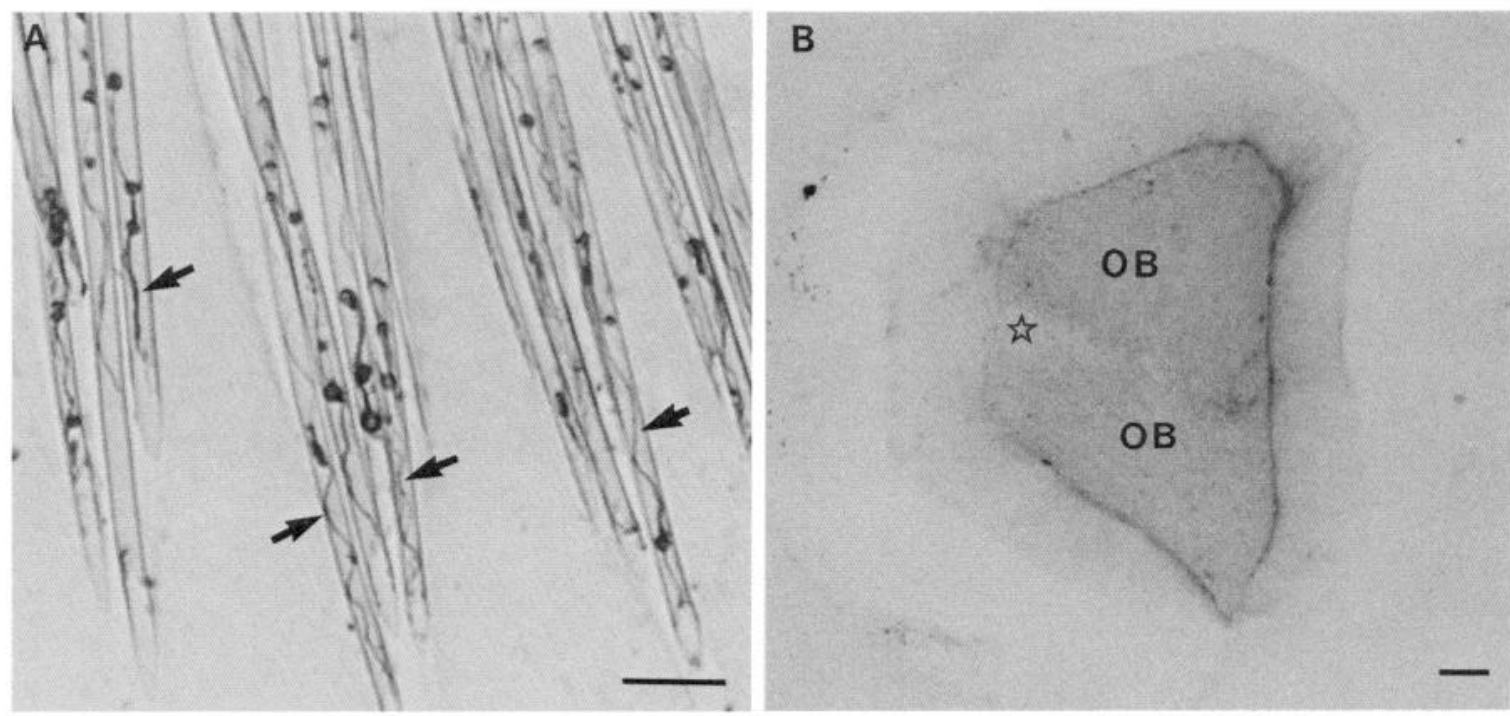

Figure 7. A, MOSA-stained dendrites (arrows) of pheromone-receptor cells in the male-specific sensilla trichodea. B, Cross section of the intracranial segment of a male AN stained by the MOSA. The axons of the pheromone-receptor cells recognized by the MOSA do not make discrete fascicles, but rather are scattered in the olfactory bundles $(O B)$. The MOSA staining therefore appears to be uniformly distributed at this magnification. The mechanosensory bundle (star) is not stained by the MOSA. Bars, $10 \mu \mathrm{m}$. 

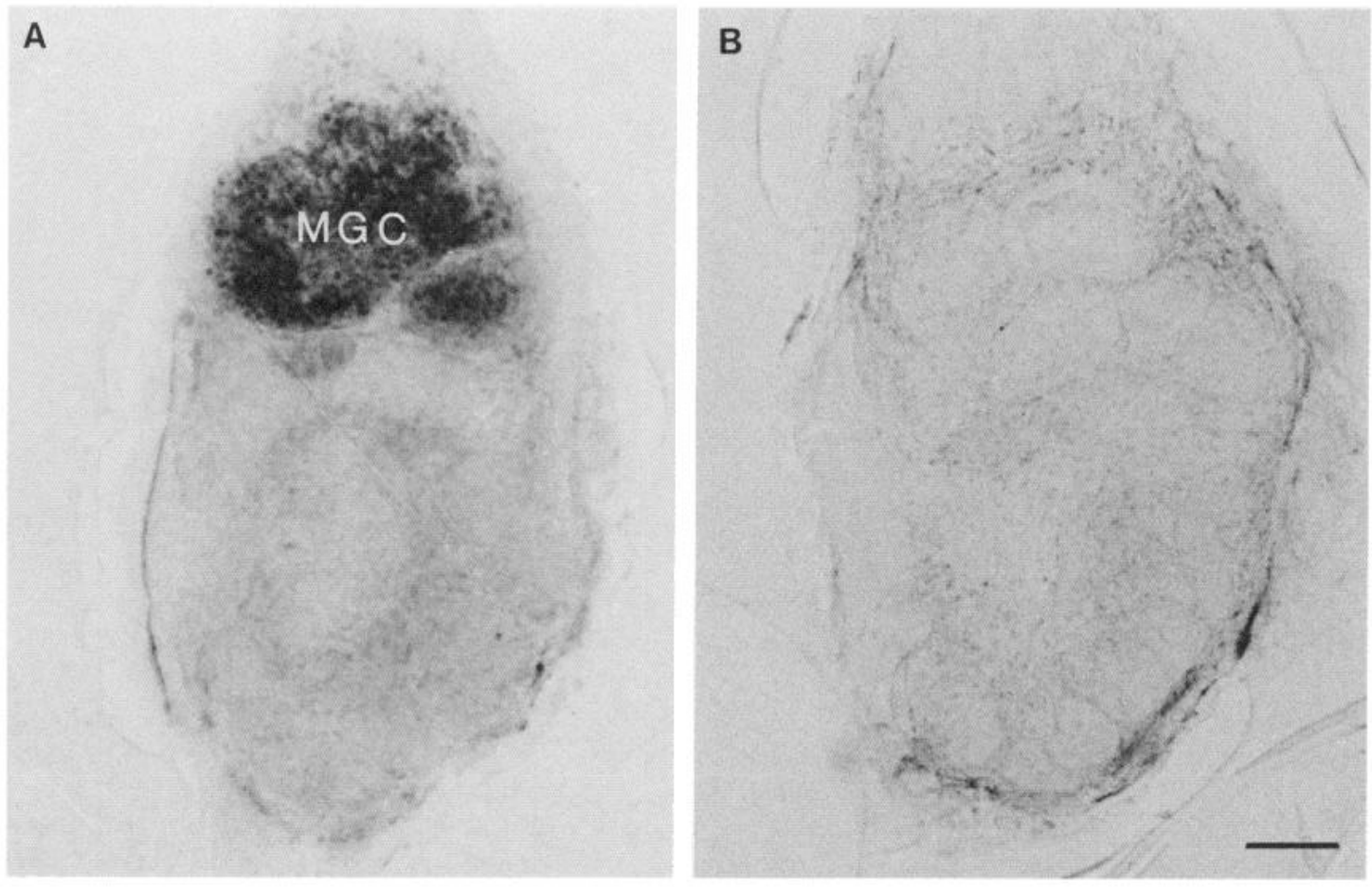

Figure 8. Frontal sections of male $(A)$ and female $(B)$ ALs stained by the MOSA. The MOSA stains the MGC in the male AL $(A)$. In the female $\mathrm{AL}$, the MGC is missing (B). No specific staining was observed. Bar, $100 \mu \mathrm{m}$.
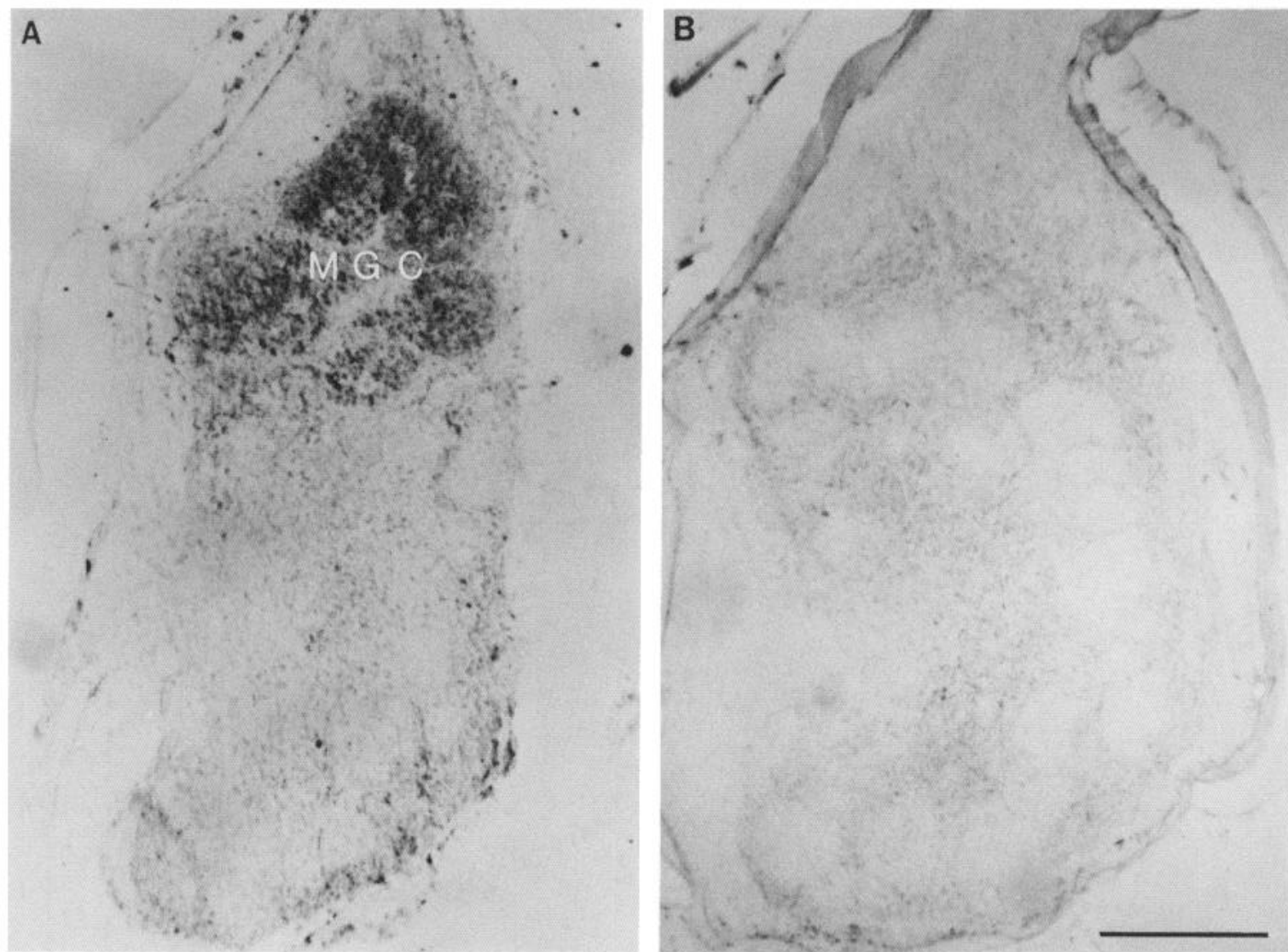

Figure 9. Frontal sections of the ALs from a female antennal gynandromorph stained by the MOSA. $A$, The AL innervated by the AN from the grafted male antenna shows MOSA staining in the MGC-like structure. $B$, The control AL, innervated by the host female AN, shows no specific MOSA staining. Bar, $200 \mu \mathrm{m}$. 


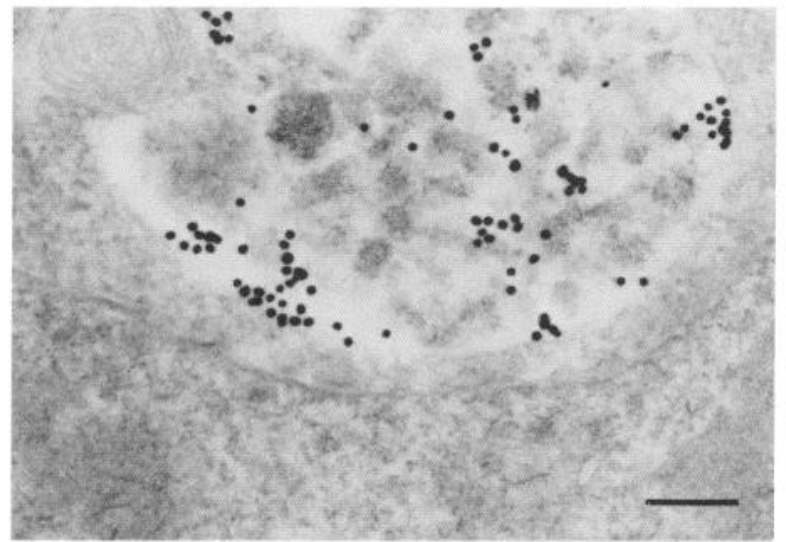

Figure 10. Electron-microscopic immunocytochemical staining by the MOSA using secondary antibody conjugated with colloidal gold (20 $\mathrm{nm})$. The gold particles are found in the cytoplasm of the initial segment of the dendrite of the male-specific ORC and appear not to be associated with a particular subcellular organelle. Bar, $0.2 \mu \mathrm{m}$.

veals that the axons of the male-specific ORCs are evenly distributed throughout the olfactory bundles in the AN (Fig. $7 B$ ). In the AL, only the male-specific MGC is stained. The "ordinary" glomeruli are not stained by the MOSA, as shown in the frontal section in Figure $8 A$. Normal female ALs, which lack the MGC, have no structures that bind the MOSA (Fig. $8 B$ ).

The MOSA immunoreactivity in the MGC reflects the axonal projections of the male-specific ORCs, as confirmed by transplantation experiments. Schneiderman et al. (1982) used a surgical procedure to produce antennal gynandromorphs, in which an AL receives sensory inputs from an antenna derived from a transplanted antennal imaginal disk of the opposite sex, and showed that formation of the MGC depends on the sex of the antenna, but not of the host. We followed the same procedure and tested the MOSA on frozen sections of the gynandromorphic ALs. The ALs of adult female Manduca innervated by ORC fibers from grafted male antennae exhibit MOSA staining in a typical male pattern (confined to the "MGC"); no MOSA staining is detectable in control, normal female ALs (innervated by sensory fibers from the female antenna) (Fig. 9).
Electron-microscopic immunocytochemistry using a secondary antibody conjugated with colloidal gold showed that the antigen recognized by the MOSA is located in the cytoplasm and is apparently not associated with any specific subcellular organelle (Fig. 10).

\section{Mechanosensory-preferring antibody (MPA)}

The MPA recognizes at least 2 classes of antennal mechanosensory cells (Fig. 11). Mechanoreceptors in the 2 basal segments of the antenna, exemplified here by receptors in the second segment (Fig. 11 $\mathrm{A}$ ), have axons that project through the mechanosensory bundle of the AN (Fig. 12A). Mechanosensory cells in the annuli of the antennal flagellum (Fig. $11 B$ ) have axons scattered in the "olfactory" bundles in the AN (Fig. 12A). Cell bodies of the ORCs are not stained by the MPA. One of the features that distinguish mechanosensory from olfactory axons is a difference in their diameters. As measured in electron micrographs, the mechanosensory axons have a relatively large diameter $(5 \mu \mathrm{m}$ for the axons from the 2 basal segments and 2 $\mu \mathrm{m}$ for the axons from the flagellum) compared to the small diameter of the olfactory axons $(0.4 \mu \mathrm{m})$ (Sanes and Hildebrand, 1976b). Single, stained mechanosensory axons can be discerned in Figure $12 \mathrm{~A}$. In the AL, the MPA labels large fibers in 2 distinct regions: the central coarse neuropil (Fig. 12B), which contains principal neurites of the AL neurons but no recognized synaptic terminals, and the mechanosensory tract (Fig. 12B), comprising mechanosensory fibers that bypass the $\mathrm{AL}$ and project to the adjacent "antennal mechanosensory and motor center."

Electron-microscopic immunocytochemistry using the MPA and an HRP-conjugated secondary antibody showed that the reaction product is associated with cytoplasmic filamentous structures and occasionally outer membranes of mitochondria in the mechanosensory axons (Fig. 13). Another antibody in our panel stains the cytoplasm of a subset of glial cells (the gliaspecific antibody-GSA; Hishinuma et al., 1985). In electron micrographs of preparations stained with the GSA and HRPconjugated secondary antibody, cytoplasmic microtubules and the outer membrane of mitochondria are labeled. When a colloidal gold-conjugated secondary antibody is used, however, the labeling of microtubules is still present, but the mitochondrial labeling is not (Hishinuma, 1986). Moreover, the DAB reaction
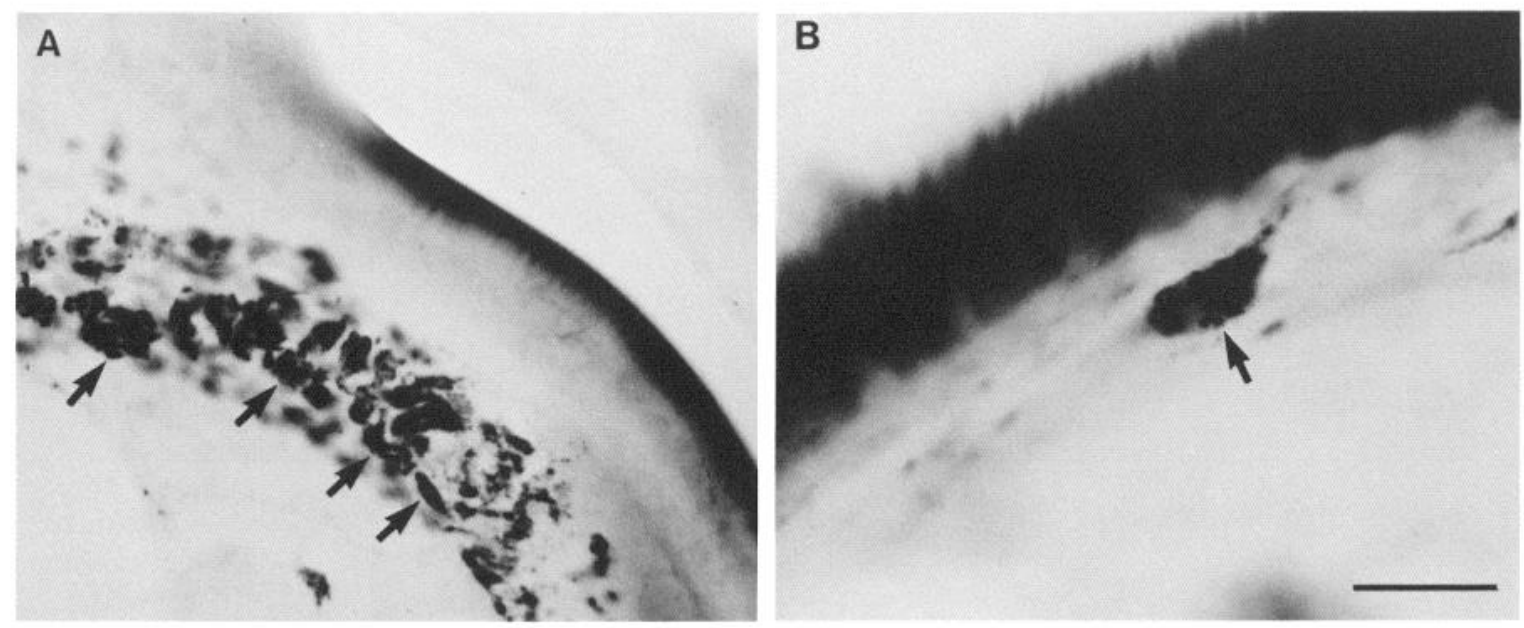

Figure 11. Immunostaining by the MPA. The MPA stains cell bodies in mechanosensory receptor cells (arrows) in cross sections of the second segment $(A)$ and one flagellar annulus $(B)$ of the antenna. Bar, $50 \mu \mathrm{m}$. 

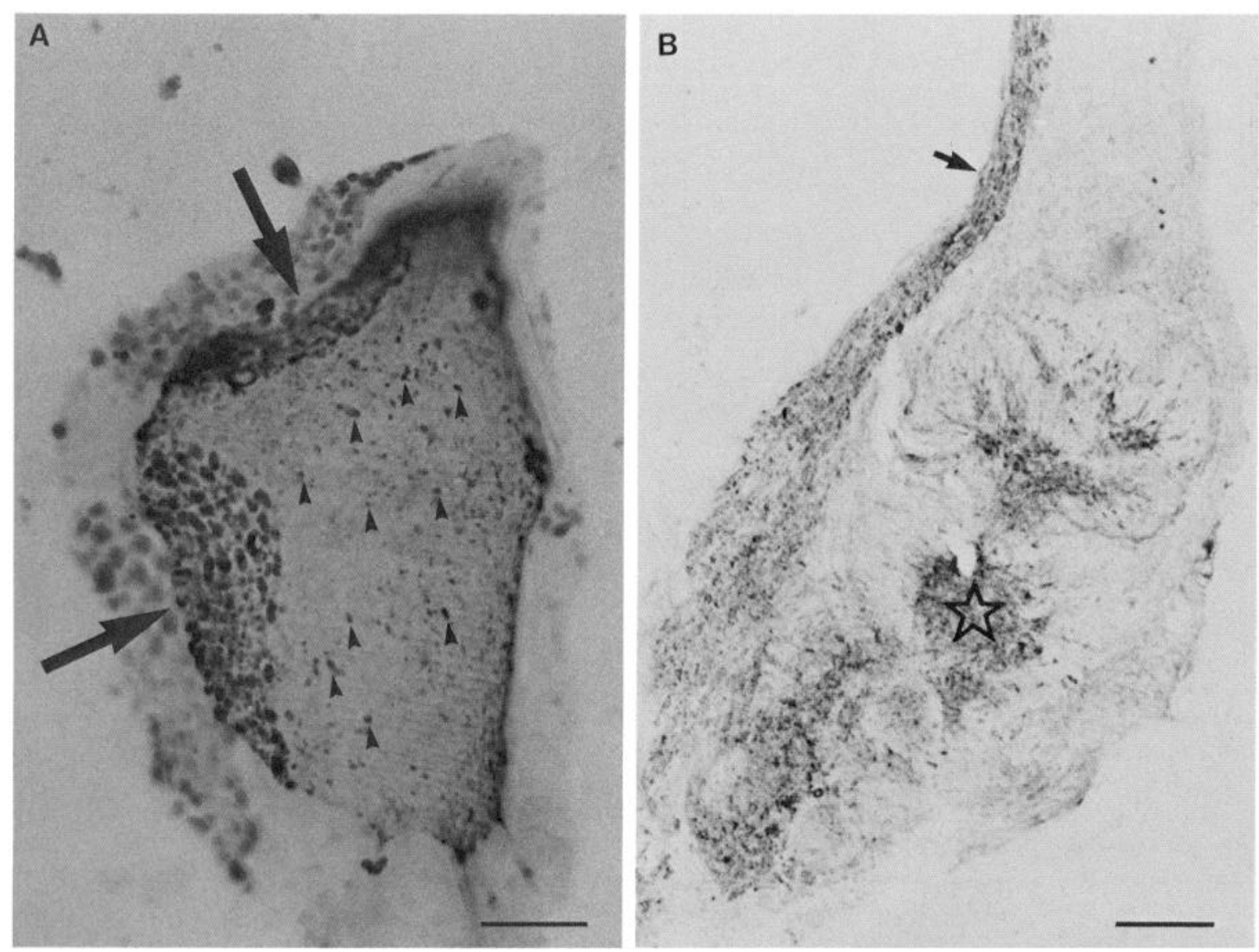

Figure 12. A, Cross section of the intracranial segment of the male AN stained by the MPA. The axons in the mechanosensory bundles (arrows) from the 2 basal segments of the antenna and the mechanosensory axons scattered in the olfactory bundles (arrowheads) from the distal flagellar annuli are stained. $B$, Frontal section of the male AL stained by the MPA. The MPA stains the central coarse neuropil (star) and the mechanosensory fiber tract (arrow). Bars: $20 \mu \mathrm{m}(A) ; 100 \mu \mathrm{m}(B)$.

product of the OSA is occasionally found on the outer membrane of mitochondria. These studies show that the reaction product nonspecifically attaches to the outer membrane of mitochondria when adjacent structures are specifically stained. When the DAB reaction product is not produced near mitochondria, their outer membrane is not stained.

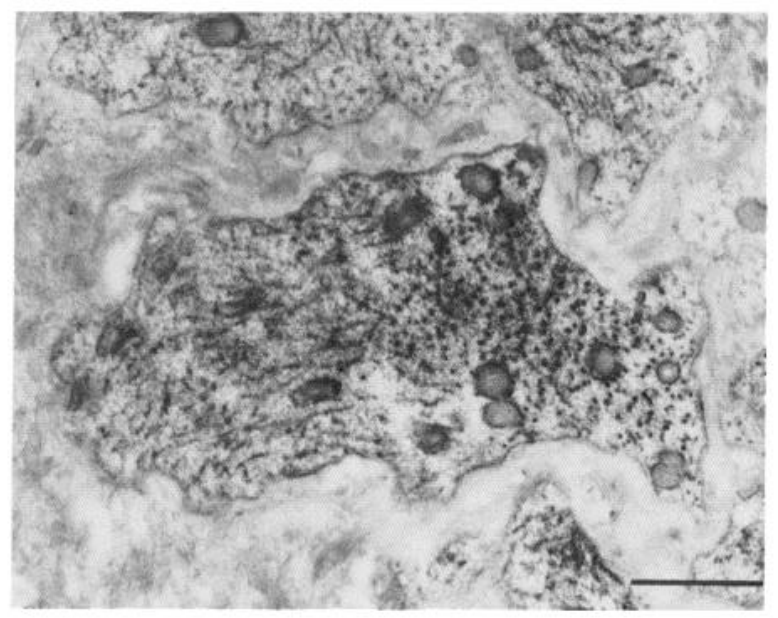

Figure 13. Electron-microscopic immunocytochemistry with the MPA using secondary antibody conjugated with HRP. The reaction product is associated with filamentous structures and mitochondrial outer membranes in the mechanosensory axons. Bar, $1 \mu \mathrm{m}$.

\section{Discussion}

\section{Olfactory-specific markers}

In the experiments reported here, 7 of 272 positive hybridoma lines, obtained from 2 AL fusions, secreted antibodies (the OSAs) that recognized the ORCs in the adult antennal and LPO sensory systems in both male and female Manduca sexta. The olfactory specificity of one of the OSAs was confirmed by immunocytochemical screening on serial sections of the whole brain and the thoracic ganglia, and by immunoblots of electrophoresed extracts of thoracic ganglia, abdominal ganglia, muscles, and fat body. The OSA binds to the cell bodies, axons, axon terminals, and initial segments of dendrites of ORCs and recognizes plasma membrane-associated antigens recovered from crude membrane fractions. We have not yet determined whether these 7 Mabs of the OSA type recognize the same molecules or not, but our ability repeatedly to generate the antibodies of the OSA class confirms that the ORCs are molecularly distinct from other types of cells in the nervous system. The finding that the OSA stains the LPO fiber tract in the CNS and the LPO glomerulus in each AL indicates that the LPO fibers share the OSA antigen(s) with antennal ORCs. This observation is consistent with the hypothesis that the LPO is an olfactory organ (Kent et al., 1986). Another antibody (the MPA) recognizes only the mechanosensory neurons in the antennal sensory system, sparing the ORCs and thus providing further evidence for molecular differentiation of the ORCs. 
In vertebrates, an olfactory-specific protein, olfactory marker protein (OMP), has been described; it was originally identified by PAGE (Margolis, 1972). It is unlikely that the antigens recognized by the OSA are the same as or closely related to OMP because (1) the OSA recognizes membrane-associated antigens, while OMP is a highly soluble protein; (2) the OSA does not stain olfactory axons in mouse and rat olfactory bulbs (B. Friedman and A. Hishinuma, unpublished observations), which are rich in OMP; and (3) the apparent molecular weights of the antigens recognized by the OSA are very different from the molecular weight of OMP (18,500 Da). Two other groups recently reported Mabs against rat ORCs (Allen and Akeson, 1985; Hempstead and Morgan, 1985). Antibody 2B8 of Allen and Akeson (1985) was produced by the fusion of spleen cells of a mouse immunized with $\mathrm{PC} 12$ rat pheochromocytoma cells and recognizes rat ORCs and other tissues. We tested 2B8 (a generous gift from Dr. Akeson) on the ORCs in Manduca, but detected no cross-reactivity. These results suggest that the OSA recognizes olfactory antigens distinct from those described in vertebrates. Furthermore, in other, unpublished experiments, we did not detect any cross-reactivity with olfactory structures in another species of moth, the Saturniid Antheraea polyphemus (kindly provided by Dr. K.-E. Kaissling), suggesting that the OSA is phyletically specific.

Biochemical analysis suggests that the antigens recognized by the OSA are processed during axonal transport. Since the OSA immunoreactivity is not detected immunocytochemically in dendrites of the ORCs, it is possible that the OSA antigens are sorted in the cell bodies to be transported to the axon terminals (Grafstein and Forman, 1980). When tissue samples enriched in receptor cell bodies and others enriched in central segments of receptor axons and axon terminals were extracted separately, the 59,000 Da protein was detected in the former, and the 66,000 Da protein in the latter; the $42,000 \mathrm{Da}$ band was found in both. The shift in apparent molecular weight $(59,000-66,000)$ from the cell bodies to the axon terminals suggests that during axonal transport, the $59,000 \mathrm{Da}$ antigen is modified to the $66,000 \mathrm{Da}$ antigen. The differential detection of the 59,000 and $66,000 \mathrm{Da}$ antigens also allows for the possibility that all of the OSA antigens are synthesized as the 42,000 Da protein, which may be processed to the 59,000 Da protein in cell bodies and to the 66,000 Da protein in central segments of ORC axons and axon terminals.

The molecular difference between the 59,000 and $66,000 \mathrm{Da}$ antigens has not yet been identified. Because endoglycosidase $\mathrm{H}$ does not cleave all carbohydrate moieties of glycoproteins, digestion with this enzyme does not prove that the difference between these proteins resides entirely in carbohydrate residues. This experiment is sufficient, however, to show that the 66,000 and 42,000 Da proteins are glycosylated. The failure of the $59,000 \mathrm{Da}$ antigen to appear in the control suggests that this antigen was not solubilized by NP-40 in citrate buffer, $\mathrm{pH} 5$, or that it was labile to the incubation at $37^{\circ} \mathrm{C}$ for $1 \mathrm{hr}$. To preserve the antigenic determinants of the $66,000,59,000$, and 42,000 $\mathrm{Da}$ OSA antigens, disulfide bonds are apparently necessary in view of the fact that treatment with the reducing agent dithiothreitol disrupted immunoreactivity on immunoblots. One hypothetical explanation is that the antigens contain subunits that are required for antigenicity and that are kept together in SDS gel electrophoresis by disulfide linkages. Consistent with the immunocytochemical data, no sex difference was revealed by the OSA on immunoblots.
The olfactory axons recognized by the OSA are fasciculated together and gathered into bundles in the $\mathrm{AN}$, separate and distinct from the bundle of mechanosensory axons from the basal segments of the antenna. One postulate of the chemoaffinity hypothesis of Sperry $(1963,1965)$ is that surface molecular differences among axons mediate route and target specificity. The expression of the OSA antigens in association with the plasma membrane, and possibly on the surface, of a specific subpopulation of axons suggests that such surface differences may exist. These results parallel those of previous studies in the leech (Hockfield and McKay, 1983; McKay et al., 1983) in which subsets of axons were shown to be distinct in membrane-associated molecules. Our ongoing developmental studies seek to determine whether the OSA antigens are present during axonal outgrowth and, if so, whether they are involved in axonal navigation and target specificity.

\section{Sexually dimorphic olfactory markers}

In this paper, we report an antibody that recognizes a sex-specific neuronal antigen. This class of Mab, the MOSA, was found only once among the 1105 hybridoma supernatant media tested. The MOSA recognizes a cytoplasmic antigen in male-specific ORCs, most or all of which are pheromone receptors. Staining with the MOSA shows that these receptor cells are biochemically unique. The function of the antigen remains to be determined, however.

Sexually dimorphic expression of polypeptides of 24,000 and $51,000 \mathrm{Da}$ in antennal sensory neurons of Manduca was reported previously (Kingan and Hildebrand, 1983). The antigen recognized by the MOSA is apparently different from those polypeptides because the sexually dimorphic expression of the MOSA antigen is detected in pharate adults, while the sexual dimorphism of the 24,000 and $51,000 \mathrm{Da}$ polypeptides is observed transiently during early phases of postembryonic development and is no longer detected in pharate adults.

\section{Functional specificity of glomeruli}

Activity-labeling studies using radioactive 2-deoxyglucose have shown that different odors cause enhanced neuronal activity in different regions of the rat olfactory bulb (Sharp et al., 1975; Stewart et al., 1979; Teicher et al., 1980; Lancet et al., 1982). HRP fiber-tracing techniques (Benson et al., 1985; Pedersen et al., 1985; Stewart et al., 1985) and immunocytochemical techniques using Mabs that stain a subset of olfactory axons (Fujita et al., 1985; Schwob and Gottlieb, 1985) have shown that the ORCs in different parts of olfactory epithelia of rats and rabbits project to certain glomeruli in the olfactory bulb. The finding that certain fascicles in the olfactory nerve of the tiger salamander were labeled with radioactive 2-dcoxyglucose upon stimulation with a particular odor (Lancet et al., 1982) supports the possibility that glomerular specificity develops at least partly as a consequence of the differential projections of axons of olfactory receptor cells with a given odor-specificity to selected glomeruli.

MOSA immunoreactivity confirms that the pheromone-receptor cells project exclusively to the MGC. Transplantation experiments have shown that, upon contact by afferent axons from male antennal ORCs, a female AL develops an MGC-like structure (Schneiderman et al., 1982). Tracing central projections of sensory fibers from single trichoid sensilla with cobalt showed that at least some of the male-specific ORCs terminate in the "MGC" in the gynandromorphic female AL (Schneiderman, 1984). Immunostaining with the MOSA confirmed that 
the axons of male-specific pheromone-receptor cells terminate exclusively in the "MGC"' in these gynandromorphic ALs, which lack the normal, genetically male target neurons. In animals whose brains have been surgically excised, subsets of the axons of the ORCs tend to segregate in groups to form neuroma-like structures (Kent, 1985). Our results, taken in conjunction with Kent's finding, suggest that the axons of the male-specific pheromone-receptor cells bear intrinsic molecular properties that mediate their fasciculation and orderly central projections in the absence of their normal synaptic targets. These axons, then, may serve as primary determinants for the formation of the MGC.

\section{Markers of neurofilaments}

Mabs against neurofilaments have been reported to identify a subset of axons in the leech (McKay et al., 1984) and discrete cell types in the mouse retina (Dräger et al., 1984) and rat cerebellum (Goldstein et al., 1983). Although we have not yet been able to ascertain whether the immunoreactivity recognized by the MPA belongs to neurofilaments or to antigen(s) associated with them, the staining pattern obtained with the MPA suggests that neurofilament proteins or neurofilament-associated proteins are heterogeneous. The MPA spares the olfactory axons, but stains the larger mechanosensory axons.

In summary, on the basis of the morphological differences between male and female ALs, we isolated a Mab (the MOSA) that specifically recognizes the pheromone-receptor cells present only in males. The MOSA and the other cell-type-specific antibodies (the OSA and the MPA) were used to examine structures in the olfactory pathway in Manduca that had been difficult to study without such markers. This study shows that the pheromone-receptor cells are molecularly distinct from other ORCs and that the ORCs are, in turn, molecularly distinct from other neurons. The resolution of remaining questions about the chemistry, processing, and functions of antigens identified by these Mabs awaits the outcome of studies in progress.

\section{References}

Adams, J. C. (1977) Technical considerations on the use of horseradish peroxidase as a neuronal marker. Neuroscience $2: 141-145$.

Allen, W. K., and R. Akeson (1985) Identification of a cell surface glycoprotein family of olfactory receptor neurons with a monoclonal antibody. J. Neurosci. 5: 284-296.

Bell, R. A., and F. A. Joachim (1976) Techniques for rearing laboratory colonies of tobacco hornworms and pink bollworms. Ann. Ent. Soc. Am. 69: 365-373.

Benson, T. E., P. E. Pedersen, P. J. Jastreboff, and G. M. Shepherd (1985) Topographical projections of septal organ receptor neurons to the main olfactory bulb in rats. Soc. Neurosci. Abstr. 11: 971.

Camazine, S. M., and J. G. Hildebrand (1979) Central projections of antennal sensory neurons in mature and developing Manduca sexta. Soc. Neurosci. Abstr. 5: 155.

Dräger, U. C., D. L. Edwards, and C. J. Barnstable (1984) Antibodies against filamentous components in discrete cell types of the mouse retina. J. Neurosci. 4: 2025-2042.

Eldred, W. D., C. Zucker, H. J. Karten, and S. Yazulla (1983) Comparison of fixation and penetration enhancement techniques for use in ultrastructural immunocytochemistry. J. Histochem. Cytochem. 31: 285-292.

Fujita, S. C., K. Mori, K. Imamura, and K. Obata (1985) Subclasses of olfactory receptor cells and their segregated central projections demonstrated by a monoclonal antibody. Brain Res. 326: 192-196.

Goldstein, M. E., L. A. Sternberger, and N. H. Sternberger (1983) Microheterogeneity ("neurotypy") of neurofilament proteins. Proc. Natl. Acad. Sci. USA 80: 3101-3105.
Grafstein, B., and D. S. Forman (1980) Intracellular transport in neurons. Physiol. Rev. 60: 1167-1283.

Hempstead, J. L., and J. I. Morgan (1985) A panel of monoclonal antibodies to the rat olfactory epithelium. J. Neurosci. 5: 438-449.

Hildebrand, J. G. (1985) Metamorphosis of the insect nervous system: Influences of the periphery on the postembryonic development of the antennal sensory pathway in the brain of Manduca sexta. In Model Neural Networks and Behavior, A. Selverston, ed., pp. 129-148, Plenum, New York.

Hildebrand, J. G., S. G. Matsumoto, S. M. Camazine, L. P. Tolbert, S. Blank, H. Ferguson, and V. Ecker (1980) Organisation and physiology of antennal centres in the brain of the moth Manduca sexta. In Insect Neurobiology and Pesticide Action (Neurotox 79), pp. 375-382, Soc. Chem. Ind., London.

Hishinuma, A. (1986) Monoclonal antibodies reveal cell-type-specific antigens in the sexually dimorphic olfactory system of Manduca sexta. Ph.D. dissertation, Columbia University, New York.

Hishinuma, A., S. Hockfield, R. McKay, and J. G. Hildebrand (1985) Monoclonal antibodies against the sexually dimorphic olfactory system of Manduca sexta. Soc. Neurosci. Abstr. 11: 919.

Hishinuma, A., S. Hockfield, R. McKay, and J. G. Hildebrand (1988) Monoclonal antibodies reveal cell-type-specific antigens in the sexually dimorphic olfactory system of Manduca sexta. II. Expression of antigens during postembryonic development. J. Neurosci. 8: 308315.

Hockfield, S., and R. McKay (1983) Monoclonal antibodies demonstrate the organization of axons in the leech. J. Neurosci. $3: 369-375$.

Kent, K. S. (1985) Metamorphosis of the antennal center and the influence of sensory innervation on the formation of glomeruli in the hawk moth Manduca sexta. Ph.D. dissertation, Harvard University, Cambridge, MA.

Kent, K. S., and J. G. Hildebrand (1985) Contributions of sensory axons and central neurons to the development of glomeruli in the antennal lobes of Manduca sexta. Soc. Neurosci. Abstr. 11: 919.

Kent, K. S., I. D. Harrow, P. Quartararo, and J. G. Hildebrand (1986) An accessory olfactory pathway in I epidoptera: The labial pit organ and its central projections in Manduca sexta and certain other sphinx moths and silk moths. Cell Tissue Res. 245: 237-245.

Kingan, T. G., and J. G. Hildebrand (1983) Sexually dimorphic expression of polypeptides in antennal sensory neurons of Manduca sexta. Soc. Neurosci. Abstr. 9: 835.

Köhler, G., and C. Milstein (1976) Derivation of specific antibodyproducing tissue culture and tumor lines by cell fusion. Eur. J. Immunol. 6: 511-519.

Laemmli, U. K. (1970) Cleavage of structural proteins during the assembly of the head of bacteriophage T4. Nature 227: 680-685.

Lancet, D., C. A. Greer, J. S. Kauer, and G. M. Shepherd (1982) Mapping of odor-related neuronal activity in the olfactory bulb by high-resolution 2-deoxyglucose autoradiography. Proc. Natl. Acad. Sci. USA 79: 670-674.

Lee, J.-K., R. Selzer, and H. Altner (1985) Lamellated outer dendritic segments of a chemoreceptor within wall-pore sensilla in the labial palp-pit organ of the butterfly, Pieris rapae L. (Insecta, Lepidoptera). Cell Tissue Res. 240: 333-342.

Margolis, F. L. (1972) A brain protein unique to the olfactory bulb. Proc. Natl. Acad. Sci. USA 69: 1221-1224.

Matsumoto, S. G., and J. G. Hildebrand (1981) Olfactory mechanisms in the moth Manduca sexta: Response characteristics and morphology of central neurons in antennal lobes. Proc. R. Soc. Lond. [Biol.] 213: 249-277.

McKay, R. D. G., S. Hockfield, J. Johansen, I. Thompson, and K. Frederiksen (1983) Surface molecules identify groups of growing axons. Science 222: 788-794.

McKay, R., J. Johansen, and S. Hockfield (1984) Monoclonal antibody identifies a 63,000 dalton antigen found in all central neuronal cell bodies but in only a subset of axons in the leech. J. Comp. Neurol. 226: 448-455.

Pedersen, P. E., P. J. Jastreboff, W. B. Stewart, and G. M. Shepherd (1985) Mapping receptor populations that project to glomeruli in the main olfactory bulb. Soc. Neurosci. Abstr. 11:971.

Sanes, J. R., and J. G. Hildebrand (1976a) Structure and development of antennae in a moth, Manduca sexta. Dev. Biol. 151:282-299.

Sanes, J. R., and J. G. Hildebrand (1976b) Origin and morphogenesis of sensory neurons in an insect antenna. Dev. Biol. 51: 300-319.

Schneiderman, A. M. (1984) Postembryonic development of a sexually 
dimorphic sensory pathway in the central nervous system of the sphinx moth, Manduca sexta. Ph.D. dissertation, Harvard University, Cambridge, MA.

Schneiderman, A. M., and J. G. Hildebrand (1985) Sexually dimorphic development of the insect olfactory pathway. Trends Neurosci. 8: $494-499$.

Schneiderman, A. M., S. G. Matsumoto, and J. G. Hildebrand (1982) Trans-sexually grafted antennae influence development of sexually dimorphic neurones in moth brain. Nature 298: 844-846.

Schwob, J. E., and D. I. Gottlieb (1985) The primary olfactory projection has two chemically distinct zones. Soc. Neurosci. Abstr. 11: 970

Sharp, F. R., J. S. Kauer, and G. M. Shepherd (1975) Local sites of activity-related glucose metabolism in rat olfactory bulb during olfactory stimulation. Brain Res. 98: 596-600.

Shorr, R. G., A. Lyddiatt, M. M. S. Lo, J. O. Dolly, and E. A. Barnard (1981) Acetylcholine receptor from mammalian skeletal muscle. Eur. J. Biochem. 116: 143-153.

Sperry, R. W. (1963) Chemoaffinity in the orderly growth of nerve fiber patterns and connections. Proc. Natl. Acad. Sci. USA 50:703710.

Sperry, R. W. (1965) Embryogenesis of behavioral nerve nets. In $\mathrm{Or}$ ganogenesis, R. L. DeHaan and H. Ursprung, eds., pp. 161-186, Holt, Rinehart and Winston, New York.
Stewart, W. B., J. S. Kauer, and G. M. Shepherd (1979) Functional organization of rat olfactory bulb analyzed by the 2-deoxyglucose method. J. Comp. Neurol. 185: 71 5-734.

Stewart, W. B., P. E. Pedersen, C. A. Greer, and G. M. Shepherd (1985) The topography of olfactory epithelium to olfactory bulb projections in the rat. Soc. Neurosci. Abstr. 11: 971.

Teicher, M. H., W. B. Stewart, J. S. Kauer, and G. M.. Shepherd (1980) Suckling pheromone stimulation of a modified glomerular region in the developing rat olfactory bulb revealed by the 2-deoxyglucose method. Brain Res. 194: 530-535.

Tolbert, L. P., and J. G. Hildebrand (1981) Organization and synaptic ultrastructure of glomeruli in the antennal lobes of the moth Manduca sexta: A study using thin sections and freeze-fracture. Proc. R. Soc. Lond. [Biol.] 213: 279-301.

Tolbert, L. P., S. G. Matsumoto, and J. G. Hildebrand (1983) Development of synapses in the antennal lobes of the moth Manduca sexta during metamorphosis. J. Neurosci. 3: 1158-1175.

Towbin, H., T. Staehelin, and J. Gordon (1979) Electrophoretic transfer of proteins from polyacrylamide gels to nitrocellulose sheets: Procedure and some applications. Proc. Natl. Acad. Sci. USA 76: 43504354. 